\title{
Contrast-enhanced ultrasound: clinical applications in patients with atherosclerosis
}

\author{
Arend F. L. Schinkel ${ }^{1} \cdot$ Mathias Kaspar $^{2} \cdot$ Daniel Staub $^{2}$
}

Received: 4 May 2015/ Accepted: 16 July 2015 / Published online: 24 July 2015

(c) The Author(s) 2015. This article is published with open access at Springerlink.com

\begin{abstract}
Contrast-enhanced ultrasound (CEUS) is increasingly being used to evaluate patients with known or suspected atherosclerosis. The administration of a microbubble contrast agent in conjunction with ultrasound results in an improved image quality and provides information that cannot be assessed with standard B-mode ultrasound. CEUS is a high-resolution, noninvasive imaging modality, which is safe and may benefit patients with coronary, carotid, or aortic atherosclerosis. CEUS allows a reliable assessment of endocardial borders, left ventricular function, intracardiac thrombus and myocardial perfusion. CEUS results in an improved detection of carotid atherosclerosis, and allows assessment of high-risk plaque characteristics including intraplaque vascularization, and ulceration. CEUS provides real-time bedside information in patients with a suspected or known abdominal aortic aneurysm or aortic dissection. The absence of ionizing radiation and safety of the contrast agent allow repetitive imaging which is particularly useful in the follow-up of patients after endovascular aneurysm repair. New developments in CEUS-based molecular imaging will improve the understanding of the pathophysiology of atherosclerosis and may in the future allow to image and directly treat cardiovascular diseases (theragnostic CEUS). Familiarity with the strengths and limitations of CEUS may have a major impact on the management of patients with atherosclerosis.
\end{abstract}

Arend F. L. Schinkel

a.schinkel@erasmusmc.nl

1 Department of Cardiology, Thoraxcenter, Erasmus MC, Rotterdam, The Netherlands

2 Division of Angiology, Department of Internal Medicine, University Hospital Basel, Basel, Switzerland
Keywords Aortic aneurysm - Atherosclerosis . Carotid artery - Contrast-enhanced ultrasound . Echocardiography $\cdot$ Endoleak $\cdot$ Endovascular aneurysm repair · Intima media thickness · Molecular imaging · Myocardial perfusion imaging . Thrombus

\section{Introduction}

Contrast-enhanced ultrasound (CEUS) is an increasingly used imaging modality in cardiovascular medicine, and has advantages for both cardiac and vascular imaging [1-3]. CEUS is characterized by the use of an ultrasound contrast agent in conjunction with ultrasound imaging. The ultrasound contrast agent consists of gas filled microbubbles, which resonate when exposed to an ultrasound beam. CEUS can be used to improve the image quality of standard ultrasound or to obtain information that cannot be assessed using standard ultrasound $[4,5]$.

CEUS has various potential applications in patients with atherosclerosis (Table 1). In those with known or suspected coronary artery disease, CEUS improves the delineation of endocardial borders, allowing an accurate assessment of left ventricular shape and function. The use of an ultrasound contrast also improves the image quality and diagnostic accuracy of stress echocardiography. In patients with a previous myocardial infarction, CEUS is useful to assess intracardiac thrombus, which may have important clinical implications.

In patients with known or suspected carotid atherosclerosis, CEUS can be used to assess the presence and extent of atherosclerosis. Moreover, CEUS allows to characterize the atherosclerotic plaque and evaluate factors that are associated with plaque rupture, including assessment of plaque surface, plaque ulceration and intraplaque 
Table 1 Overview of clinical application of contrast-enhanced ultrasound in cardiovascular diseases

\begin{tabular}{ll}
$\begin{array}{l}\text { Field of } \\
\text { application }\end{array}$ & Clinical indication \\
\hline Cardiac & $\begin{array}{l}\text { Endoluminal border delineation to assess left ventricular volumes and function and detection of intracardiac thrombus } \\
\text { Visualization of wall motion and thickening to assess myocardial ischemia and viability } \\
\\
\text { Quantification of myocardial perfusion }\end{array}$ \\
Earotis & $\begin{array}{l}\text { Endoluminal border delineation to depict hypoechogenic plaques, plaque irregularities and ulcerations, distinguish very high- } \\
\text { grade stenosis from complete occlusion } \\
\end{array}$ \\
& Detection and quantification of intraplaque neovascularization to risk stratify atherosclerotic lesions and to monitor \\
& Detection of dissection membrane and re-entry and discrimination of true and false lumen in abdominal aortic dissection \\
Aorta & Endoluminal border delineation in abdominal aortic aneurysm to detect intraluminal thrombus \\
& Detection and classification of endoleaks after endovascular aortic aneurysm repair (EVAR)
\end{tabular}

vascularization. Furthermore, CEUS imaging can further increase the diagnostic performance in different aortic pathologies, particularly the detection and characterization of endoleaks following endovascular treatment of abdominal aortic aneurysms (AAAs).

This review of literature will explain the principles and ultrasound acquisition settings, and will focus on cardiac and vascular including carotid and aortic applications of CEUS.

\section{Principles and settings of CEUS}

\section{Ultrasound contrast agents}

A number of ultrasound contrast agents has been developed and is commercially available. The ultrasound contrast agent typically consists of microbubbles with a protein or lipid shell filled with an inert gas. These microbubble contrast agents are stable, and are strong reflectors and resonators when exposed to an ultrasound beam. An overview of commercially available contrast agents is provided in Table 2. The safety of intravenous administration of an ultrasound contrast agent has been confirmed in millions of patients [6, 7]. Contraindications for the administration of the contrast agents are: known allergy to the contrast agent, large right to left shunt, and an unstable clinical condition. It is recommended to use a protocol in the echo laboratory for early recognition of side-effects and so that in the event of an allergic reaction immediate treatment can be started [8].

\section{Ultrasound system settings}

The currently available high-end ultrasound systems have preprogrammed settings for CEUS. These settings can be slightly adapted to optimize the CEUS study. To avoid destruction of the microbubbles, which are fragile, a low mechanical index $(0.1-0.3)$ or middle-high (0.3-0.5) mechanical index is selected [8]. A low mechanical index allows continuous image acquisition, whereas a middlehigh mechanical index requires intermittent imaging (for example acquisition of 1 frame every 2 or 3 cardiac cycles) allowing the replenishment of destructed microbubbles. Depending on the ultrasound system settings, harmonic imaging is used which is based on differences in ultrasound reflection by tissue and by the contrast agent. The contrast agent does not only reflect the ultrasound at the transmitted frequency but also at higher harmonic frequencies, allowing to distinguish contrast agent from tissue. Other contrast-specific ultrasound methods are based on the transmission of multiple ultrasound pulses. Mostly, a combination of pulses is transmitted which are out-ofphase (pulse inversion), or differ in amplitude (power modulation), depending on the manufacturer of the ultrasound system.
Table 2 Overview of commercially available ultrasound contrast agents

\begin{tabular}{llll}
\hline Contrast agent & Manufacturer & Shell & Gas \\
\hline Definity & Lantheus medical imaging & Lipid & Octafluoropropane \\
Levovist & Schering AG & Galactose & Air \\
Optison & GE healthcare & Albumin & Octafluoropropane \\
SonoVue & Bracco diagnostics & Lipid & Sulfurhexafluoride \\
Sonazoid & GE healthcare & Lipid & Perfluorocarbon \\
\hline
\end{tabular}




\section{CEUS acquisition}

After explanation of the imaging modality and obtaining informed consent of the patient, the CEUS examination can be started. First, a venous infusion line is placed, and after preparation of the contrast agent according to the instructions of the manufacturer, the ultrasound contrast agent is administered intravenously. The ultrasound contrast agent can be injected as a bolus which is practical and will give good imaging results in most circumstances. Alternatively, the ultrasound contrast agent can be administered using a continuous infusion, which provides a stable concentration of contrast agent in the circulation and therefore has advantages for the assessment of myocardial perfusion. After intravenous administration, the ultrasound contrast agent travels through the cardiovascular system. The microbubbles behave as red blood cells and are strict intravascular tracers. Because of their small diameter, the microbubbles are able to pass the pulmonary circulation. After administration, the contrast agent can be visualized for minutes. When the microbubbles are shattered, the shell is removed through the reticuloendothelial system, while the inert gas is exhaled.

\section{CEUS: cardiac applications}

\section{Endocardial border delineation}

\section{Assessment of left ventricular volumes and function}

An accurate detection of the endocardial border is highly relevant in patients with known or suspected coronary artery disease. Up to $15 \%$ of these patients have a moderate to poor image quality at standard echocardiography, because of comorbidity such as obesity and chronic pulmonary disease. CEUS significantly improves the detection of the endocardial border, which is clinically relevant for an accurate assessment of left ventricular volumes and systolic left ventricular function [9]. The use of an ultrasound contrast agent improves the assessment of the left ventricular ejection fraction, and thereby has an impact on clinical care [10]. Among other parameters, the left ventricular ejection fraction determines the medical treatment, therapy with an implantable cardioverter defibrillator and finally the prognosis of the patients.

\section{Contrast stress echocardiography}

Stress echocardiography provides information on the presence and extent of myocardial ischemia. Moreover, stress echocardiography allows assessment of myocardial viability in patients with ischemic cardiomyopathy. A good visualization of wall motion and thickening is needed for an accurate interpretation of stress echocardiography. Because the criteria for myocardial ischemia and myocardial viability are based on wall motion abnormalities, an accurate visualization of all walls of the left ventricle is required. Ultrasound contrast agents provide an improved endocardial border delineation, and result in a better reproducibility in wall motion analysis even by less experienced readers $[11,12]$. The use of an ultrasound contrast agent is recommended during stress echocardiography in all patients with suboptimal image quality, in whom $\geq 2$ segments of the left ventricle are not adequately visualized. The administration of an ultrasound contrast agent is particularly relevant for visualization of the anterior and lateral wall, because image quality is often suboptimal in those areas.

\section{Intracardiac thrombus}

In patients with ischemic cardiomyopathy and a suspected intracardiac thrombus, CEUS may be highly useful. In these patients the endocardial border in the left ventricular apex is frequently difficult to delineate, and clutter or reverberation artefacts near the apex may be present during standard echocardiography. CEUS allows a reliable assessment of the left ventricular cavity and can be used to exclude or confirm the presence of an intracardiac thrombus (Fig. 1). A study in 409 patients demonstrated that standard echocardiography was nondiagnostic for the exclusion or detection of thrombus in $46 \%$ of the cases; a selection of these patients subsequently underwent CEUS, and the addition of an ultrasound contrast agent led to a diagnostic study in $90 \%$ of the cases [13]. Recent multimodality imaging studies have confirmed that CEUS has a higher diagnostic accuracy compared to standard echocardiography for the assessment of intracardiac thrombus, and demonstrated that contrast-enhanced magnetic resonance imaging may be even superior [14, 15].

The evaluation of cardiac thrombus by CEUS may have a direct impact on the management of the patient, and may lead to changes in medical therapy (anticoagulation). Additionally the detection of an intracardiac thrombus by CEUS may prevent defibrillation threshold testing in patients with an implantable cardioverter defibrillator (ICD).

\section{Myocardial perfusion imaging}

In patients with known or suspected coronary artery disease, CEUS may be useful for the assessment of myocardial perfusion (Fig. 2) [16]. Myocardial perfusion imaging requires a stable concentration of the ultrasound contrast agent in the circulation, that can be best achieved with intravenous administration using a continuous pump 


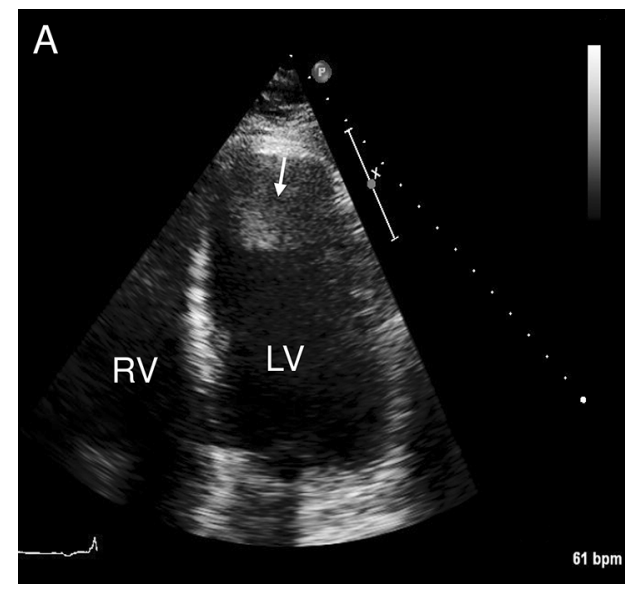

Fig. 1 Assessment of an intracardiac thrombus using CEUS. A 61-year old man with a history of a large apical-anterior myocardial infarction was referred for echocardiography for the evaluation of cardiac thrombus. a Standard echocardiography (apical 4 chamber view) demonstrates an abnormality in the left ventricular apex which

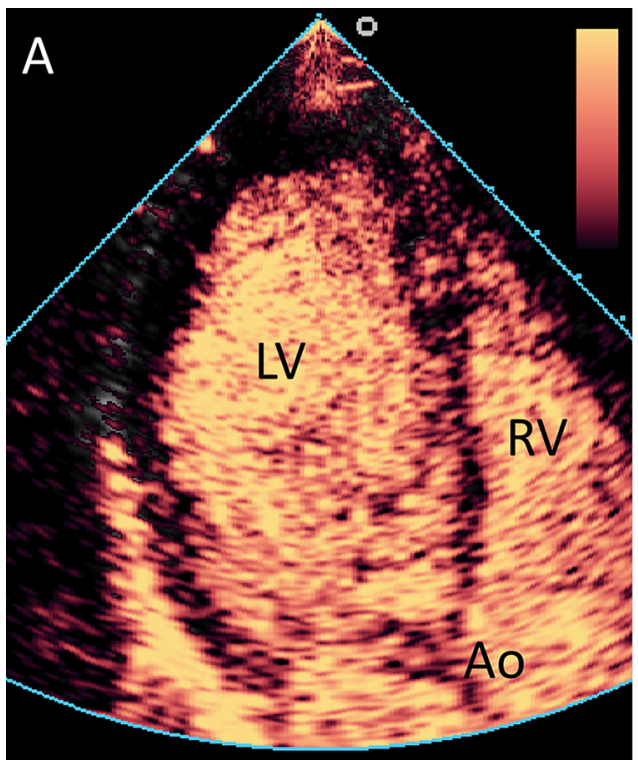

Fig. 2 Assessment of myocardial perfusion using CEUS. Example of an abnormal myocardial perfusion echocardiogram. a Apical three chamber view. After administration of the contrast agent, a high mechanical index flash is given to destroy the contrast agent that is present in the myocardium. Thereafter, the left ventricular

infusion system. After a high mechanical index ultrasound flash to destruct all intramyocardial ultrasound contrast agent, the replenishment of the contrast agent into the myocardium is recorded. Several software packages were developed to measure the video-intensity of the myocardial perfusion replenishment and to quantify myocardial perfusion defects. Although CEUS myocardial perfusion imaging has been successfully used in multiple studies $[16,17]$, the use of this imaging modality for this specific

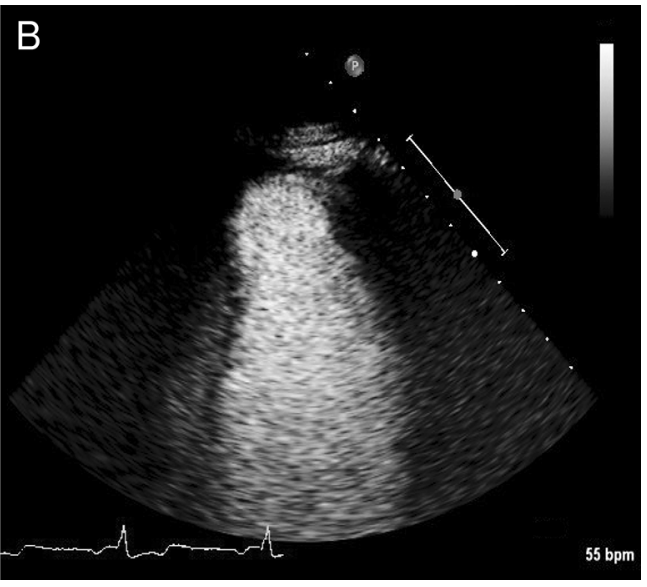

was a suspected thrombus (arrow). b CEUS demonstrates that there is actually no thrombus in the left ventricular apex. The abnormality that was observed on standard echocardiography was probably a reverberation artefact

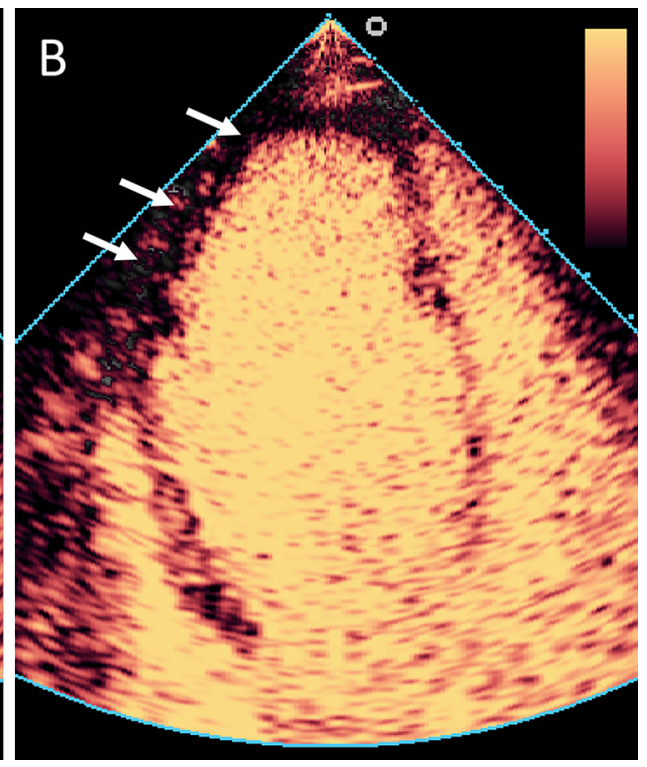

myocardium does contain no or only a limited amount of contrast agent. Ao aorta, $L V$ left ventricle, $R V$ right ventricle. b After a short period, the myocardium is filled with blood and contrast agent. There is an apical and lateral perfusion defect visible (arrows), indicating a significant coronary stenosis. Example reproduced from [84]

application clinical practice is still limited by a relatively high intra- and interobserver variability.

\section{CEUS: carotid applications}

\section{Standard carotid ultrasound}

In daily routine, the use of standard carotid ultrasound to detect atherosclerotic wall alterations including carotid 
plaques and stenosis is well established. The main focus of such an investigation is the measurement of Doppler velocities within carotid lesions in order to determine the grade and therefore also the severity of the stenosis. Beside this morphological and hemodynamic information on conventional ultrasound which represent s a late manifestation of atherosclerosis, also early changes of the atherosclerotic process can be depicted by using high frequency B-mode ultrasound. It is well known that small changes in thickening of the carotid intima-media (c-IMT) can be detected using this imaging method, and represent an early surrogate marker of systemic atherosclerosis [18]. Furthermore, B-mode ultrasound can also be useful not only to detect but also to characterize atherosclerotic plaque by identifying surface irregularities and echogenicity of the lesion itself. In large prospective epidemiological studies, it has been shown that an increased c-IMT is associated with future cerebrovascular and cardiac events [19]. However, in addition to the traditional cardiovascular risk factors to predict individuals risk, the measurement of c-IMT has limited value [20]. On the other hand, the combination of c-IMT and the presence of carotid plaque has the potential to significantly increase risk prediction in addition to traditional cardiovascular risk factors alone [21].

Nevertheless, it is still controversial if the incorporation of c-IMT and carotid plaque to cardiovascular risk assessment strategies is really beneficial in the clinical setting [22]. Therefore, it seems to be useful to include further plaque characteristics which can be analyzed by ultrasound imaging for a better risk stratification of individual patients [23]. Based on different studies, patients with hypoechoic carotid lesions and plaque ulcerations on B-mode ultrasound have more cerebrovascular and cardiac events in the future, and therefore, this kind of alterations are associated with higher cardiovascular risk [3, 24-27].

\section{CEUS for luminal enhancement of the carotid artery}

During the last years CEUS imaging of the carotid artery has been widely investigated in order to analyze carotid plaque characteristics in more detail compared to standard ultrasound alone. Usually, a linear vascular ultrasound probe with medium frequency (e.g. 3-9 MHz) is most suitable for carotid artery imaging with CEUS. Typically, on CEUS imaging the carotid lumen is enhanced shortly after injection of the contrast agent. The adventitia layer also appears enhanced, whereas the intima-media layer remains hypoechogenic. Using this imaging technique, smaller vessel wall irregularities and hypodense plaques, as well as plaque ulcerations can be depicted much better than using standard ultrasound alone [28] (Fig. 3).
Recently, asymptomatic patients with high cardiovascular risk have been investigated using carotid CEUS imaging in order to detect subclincal atherosclerotic lesions [29]. The researchers found that this additional use of CEUS increases the detection rate of predominantly hypoechogenic carotid plaque. Therefore, carotid CEUS may be useful to evaluate patients for subclinical atherosclerosis. Furthermore, different reports also emphasize that CEUS imaging could be very useful to separate a carotid occlusion from a very narrow stenosis [30, 31]. Carotid CEUS imaging could also be very beneficial for analyzing restenosis after carotid stenting [32].

\section{CEUS for carotid plaque neovascularization}

Carotid CEUS imaging is not only useful for better delineation of the endoluminal border of the carotid artery but also for a deeper analysis of plaque characteristics by visualizing the microvessels within the atherosclerotic lesion itself [2]. These microvessels have been known to be derived from the physiological existing vasa vasorum in the adventitia layer of the large- and middle-size arteries which can proliferate into the atherosclerotic plaque. In different histological studies, the increase of intraplaque neovascularization has been investigated and seems to be triggered by hypoxia and inflammation. Importantly, plaque progression and vulnerability, eventually leading to the vascular event seems to be closely related with this intraplaque neovascularization [33]. Particularly in symptomatic carotid stenosis, such microvessels of larger amount have been documented. Interestingly, this network of small vessels seems of immature nature and leakier than normal microvessels which make such plaque more prone for inflammatory cell recruitment and intraplaque hemorrhage, eventually leading to plaque rupture and vascular event. Hellings and co-workers published an important prospective study in which specific histological characteristics of carotid stonsis after carotid endarterectomy were analyzed with regard to future vascular events [34]. Patients with higher vessel density and more intraplaque hemorrhage on histology had during the 3 years follow-up more vascular events. These results emphasize again that higher neovascularization within the carotid atherosclerotic plaque seems to be a marker of cardiovascular vulnerability with a certain prognostic importance. Therefore, imaging modalities which help to visualize intraplaque neovascularization non-invasively could be very useful for further stratification and prevention of cardiovascular risk [2,35].

Particularly, carotid CEUS imaging seems to be of great value for the identification and quantification of such microvessels within carotid arteriosclerotic lesions. Several researchers analyzed this intraplaque neovascularization on CEUS imaging in different animal models [36-38] and also 

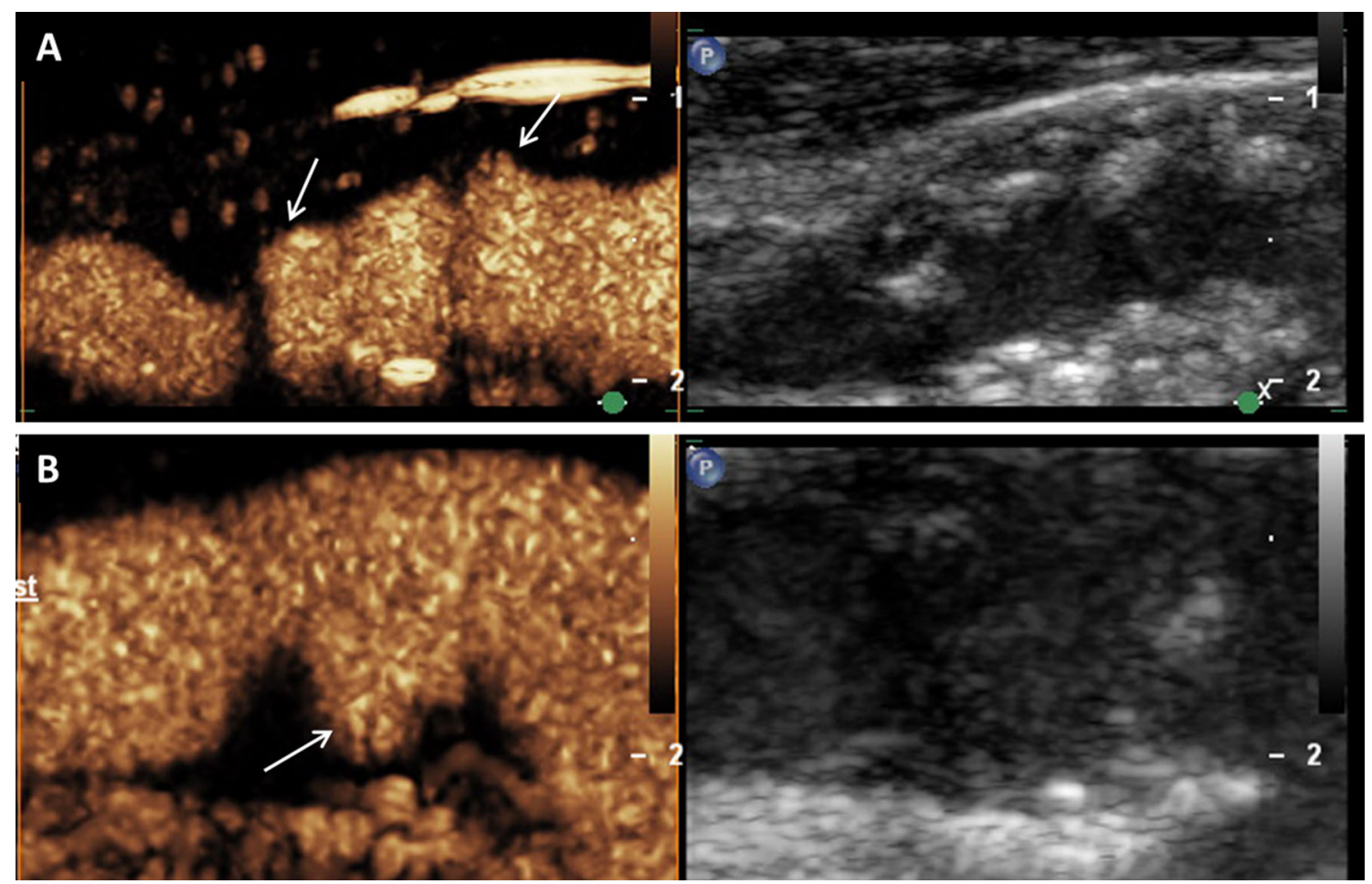

Fig. 3 Assessment of vessel wall irregularities and plaque ulcerations on carotid artery using CEUS. a Mixed hypo- and hyperechoic plaques at the carotid bulb on B-mode ultrasound (right side) and CEUS imaging (left side) with surface irregularities (arrows).

in patients scheduled for carotid endarterectomy [39, 40]. They found good correlations between the grade of intraplaque neovascularization on CEUS and the amount of microvessels on histology. Usually, the degree of intraplaque neovascularization on CEUS was determined based on a visual interpretation using a scoring system for the grading (e.g. no, moderate, extensive enhancement) (Fig. 4). Some investigators tried to quantify the degree of intraplaque neovascularization by measuring video-intensity within the atherosclerotic lesion [41-43]. They also documented a very good correlation between this quantitative approach to measure the degree of intraplaque neovascularization and microvessel density on histology.

Recently, van den Oord published the results of a new quantification tool based on custom developed software which uses a motion tracking algorithm [44]. Such a more accurate quantitative analysis method to assess intraplaque neovascularization seems to be mandatory for clinical application of CEUS imaging in the future. Interestingly, the researchers found also a good correlation between the degree of intraplaque neovascularization using this quantification tool and the previous mentioned visual based approach on carotid CEUS imaging. This assessment seems also to be very reproducible with low intra-observer and inter-observer variability. Similar to this study, other studies b Plaque ulceration (arrow) on CEUS imaging (left side) at the origin of the internal carotid artery not detected on B-mode ultrasound (right side)

used also a quantitative software based approach to determine the degree of intraplaque neovascularization on carotid CEUS imaging $[45,46]$. They found a good correlation with histological analysis of plaque vascularization, too.

Our research group also analyzed almost 300 atherosclerotic carotid lesions with standard ultrasound and CEUS imaging [47]. We measured intraplaque neovascularization on CEUS using the previously mentioned visual based scoring system (no, moderate or extensive enhancement). In line with previous published results and with the concept that hypoechoic plaques were more vulnerable, we found that echogenicity on B-mode ultrasound was inversely correlated with the degree of intraplaque neovascularization on CEUS. Hypoechoic plaques were significantly more often more vascularized on CEUS imaging. We also revealed that more severe atherosclerotic lesions based on the degree of stenosis and plaque thickness were also more vascularized on CEUS imaging (Fig. 5). One recent study also documented that neovascularization within carotid stenosis detected by CEUS was associated with the presence of microembolic signals known as another marker of plaque vulnerability using transcranial color Doppler monitoring [48].

Furthermore, clinical vascular symptoms have been correlated with the presence of intraplaque neovascularization 

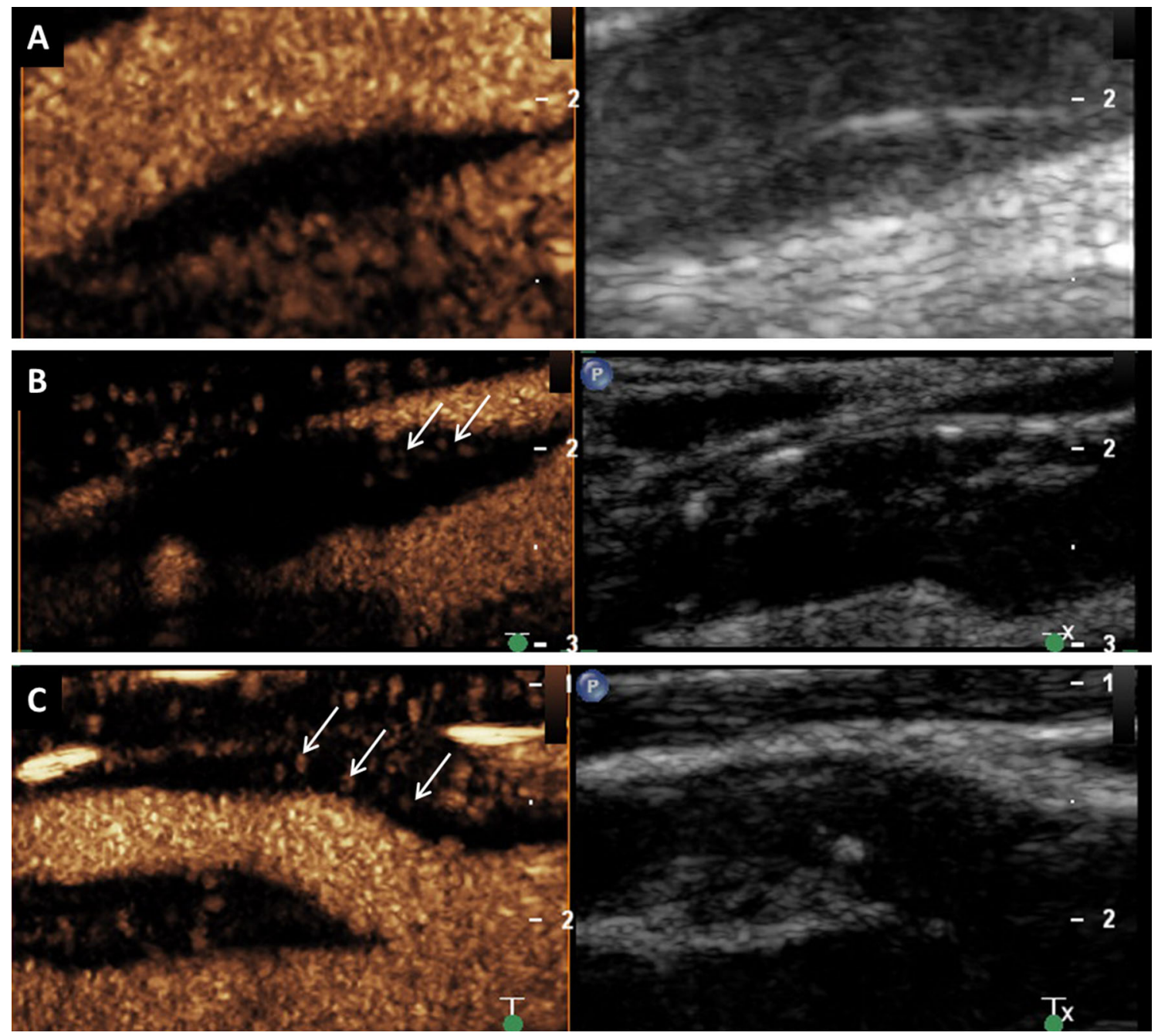

Fig. 4 Visual based grading of intraplaque neovascularization on CEUS imaging. a No enhancement: Small plaque on the fare wall of the internal carotid artery on B-mode ultrasound (right side) without intraplaque neovascularization on CEUS imaging (left side). b Moderate enhancement: Mixed hypo- and hyperechoic plaques at the carotid bulb on B-mode ultrasound (right side) and CEUS imaging (left side)

on CEUS. Retrospective studies including our own have shown pronounced intraplaque neovascularization on carotid CEUS imaging in patient with past cerebrovascular and coronary events [43, 49-52]. This result supports the concept that the vascular risk assessment based on the carotid vessel wall alterations, particularly the degree of intraplaque neovascularization is not limited to the cerebrovascular bed but also generalizable to the coronary and maybe also the peripheral vascular system.

The use of carotid CEUS imaging to assess intraplaque neovascularization in order to have a new, non-invasive tool for better risk stratify carotid lesions and patients has been recommended by the latest EFSUMB guidelines on the clinical practice of CEUS on non-hepatic applications [53]. Even though there are no clinical date, the guidelines with moderate intraplaque neovascularization on the plaque shoulder (arrows). c Extensive enhancement: Hypoechoic plaque at the origin of the internal carotid artery on B-mode ultrasound (right side) and CEUS imaging (left side) with extensive intraplaque neovascularization including the plaque core (arrows)

also emphasize the benefit of carotid CEUS imaging also for the assessing the response to anti-atherosclerotic therapy. Interestingly, recent published paper demonstrated in rat model, that atorvastatin significantly inhibits the development of adventitial vasa vasorum and progression of atherosclerosis measured by CEUS and intravascular ultrasound imaging independent of lowering the cholesterol level [54]. Therefore, monitoring of atherosclerotic lesions by CEUS imaging could indeed be clinically beneficial in the future.

Actual good clinical indication for CEUS imaging is the detection of small hypoechoic and ulcerated plaque by a better delineation of the endovascular border based on the luminal enhancement. Furthermore, CEUS imaging for the quantification of intraplaque neovascularization seems to 
Fig. 5 Intraplaque

neovascularization within carotid stenosis on CEUS imaging. a 77-year-old patient with asymptomatic high-grade stenosis at the origin of the right internal carotid artery on Duplex ultrasound. b Extensive intraplaque neovascularization within the carotid stenosis at the near wall on CEUS imaging (arrows) and moderate neovascularization at the fare wall (arrow)
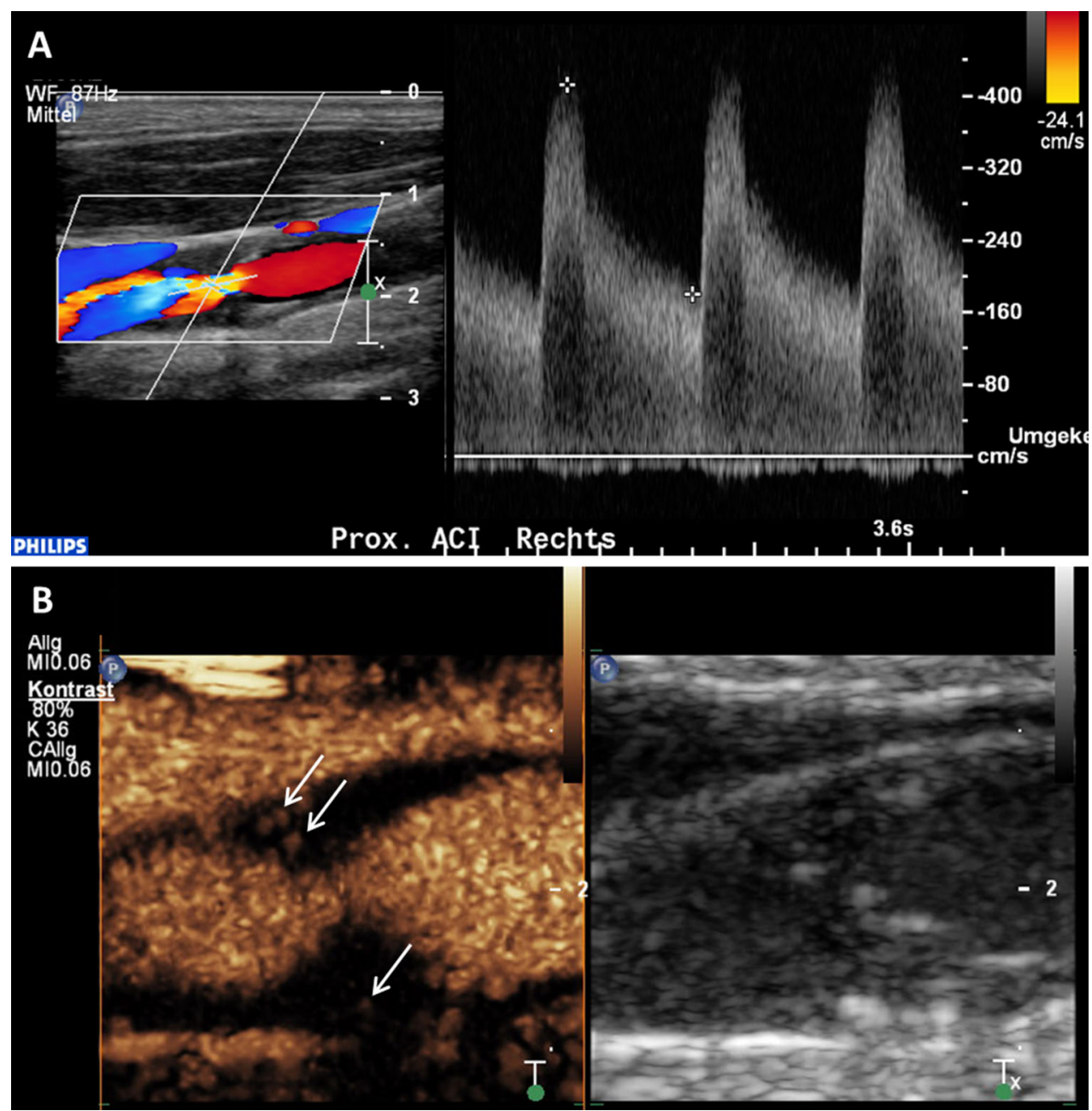

be a good tool for better risk stratification of atherosclerotic carotid stenosis and patients with carotid plaques. This strategy could improve the prediction of future vascular events and may be helpful for better treatment selection. Particularly, in patients with asymptomatic carotid stenosis, CEUS imaging could be beneficial to select those patients who should assign for carotid endarterectomy or stenting. However, further prospective randomized studies to analyze this approach are mandatory before incorporating such a concept in a daily clinical algorithm.

\section{CEUS: aortic applications}

Also the use of standard ultrasound in the diagnostic approach of the abdominal aorta is well established. In recent years the use of CEUS increasingly allowed a more differentiated view of the aortic wall by a better demarcation of the aortic lumen and its branches. In the following part we will discuss the main implications of CEUS in imaging different atherosclerotic pathologies of the abdominal aorta.
Aneurysm dissecans

The clinical presentation of a dissection of the abdominal aorta varies widely and the prediction of the progression of a dissection is challenging, and therefore more than onethird of aortic dissections remain initially undetected and nearly $30 \%$ are diagnosed post mortem by autopsy [55-57].

Due to its high spatial resolution and its high rating in routing therapy the definite diagnosis or the exclusion of an aortic dissection is made by computed tomography angiography (CTA). Conventional ultrasound is helpful in early stages of finding the diagnose in an emergency set-up with suspected dissection of the abdominal aorta, whereas the addition of contrast agent leads to a better differentiation of true and false lumen, because the latter, if not full of thrombus, usually shows contrast flow during late phase or at least with noticeable detention [58]. Clevert et al. [59] evaluated 35 patients with abdominal aortic dissection using standard ultrasound, CEUS imaging and CTA. They found that sensitivity of CEUS imaging to detect dissection 
membrane was $97 \%$ using CTA as gold standard which was much better than standard ultrasound alone (sensitivity $68 \%$ ). Particullarly, in search of the entry or re-entry of the dissection, CEUS can be used, especially to detect small dissection membranes, which were not able to be visualized with B-Mode or color Doppler.

\section{Aneurysm verum}

Over the last decade standard ultrasound was not only entrenched as a screening method for AAA but also as a valid method during its routine follow-up [57]. Different clinical reports have showed the importance of CEUS in imaging the aneurysm sack with its perfused lumen and the distinction of thrombotic structures [56, 58]. Interestingly, even in the setting of ruptured aortic aneurysm, it seems, that collecting contrast-specific images such as enhancement of the aortic wall or contrast containing extravasates preoperatively does not delay surgery [60].

\section{Endovascular aortic aneurysm repair (EVAR) and Endoleak}

Catheter based endovascular aneurysm repair (EVAR) is meanwhile a worldwide established alternative to conventional open surgery replacement in treating an aortic aneurysm and provides a minimal invasive option especially in patients with fitting characteristics of the aorta [61].

However, EVAR shows to a certain extent complications that are procedure associated and gain in relevance especially with prolonged survival. These are predominantly so called endoleaks which occur in up to $45 \%$ of the cases and are characterized by a persistent blood flow into the aneurysm sac from outside the endoprothesis [62]. Here, a progressive aneurysmal enlargement by flow-induced pressure increase could lead to a relocation of the stent graft or in the further course even to the rupture of the aneurysm sac. Therefore, the detection of such an enlargement of the aneurysm sac makes a reintervention often necessary. Nowadays, complication controls are often made by contrast CTA [63]. However, because of the radiation burden as well as the potentially nephrotoxic effect of the contrast medium with frequent use, the role of routine follow-up of patients using CTA is controversial [64]. The long term prognosis after EVAR is strongly dependent on the renal function and could be compromised by repetitive application of CT-specific contrast agents, and therefore CEUS appears to be an enticing option [65]. CEUS allows the real-time assessment of flow, which is highly useful for the detection and classification of endoleaks (Fig. 6). A meta-analysis showed an accumulated specificity of $98 \%$, respectively a sensitivity of $88 \%$, for the finding of an endoleak and the authors stated a superiority of CEUS in comparison with standard ultrasound, which is congruent with previously collected data $[65,66]$.

Due to the strictly intravascular distribution and resonance pattern of the contrast agent, CEUS can also be used for detection of endoleaks that are difficult or even impossible to be displayed by CTA due to low flow rates. In one study, CEUS was used additionally in a small number of patients that did not show any signs of endoleak or endograft irregularities during CTA despite increase in aneurysm diameter after EVAR and surprisingly revealed in $100 \%$ of the participants an endoleak and helped to classify it correctly in $80 \%$ of the cases. Results were confirmed by a final subtraction angiography and led to the conclusion that in the event of an unclear aneurysm enlargement after EVAR, CEUS represents a promising diagnostic tool [67]. In addition, CEUS can also be used intraoperatively for early detection of endoleaks or to find appropriate landing zones during EVAR and so important information can be collected to carry out immediately a correction of the stent position during the intervention [68, 69].

Another application in the field of CEUS for endoleak detection, especially to differentiate those with variable flow rates, is the by contrast harmonic imaging optimized perfusion analysis [70]. Hereby, reperfusion of abdominal aneurysm sac after EVAR is determined by a time intensity curve, which, in turn, is derived from bolus administration of contrast agent.

\section{CEUS for post-interventional follow-up after EVAR}

In general, CEUS is at least equated to CTA in the diagnostic performance in terms of recognition and classification of endoleaks. This led to the conclusion of some authors that for future references CEUS might play a deciding role in post-interventional follow-up after EVAR [71]. In a prospective observational study of more than 100 patients after EVAR to examine the accuracy rate of various diagnostic procedures compared to conventional angiography CEUS proved as superior against color Doppler and as equivalent against CTA or MRA [72]. Moreover, the authors even conclusively stated a superiority of CEUS in comparison to CTA with respect to the classification of endoleaks. This is in turn connected to another smaller analysis, in which patients after EVAR were examined over a longer period of time on endoleaks, whereby even insidious ones or those with low flow could be visualized. However, due to continuous administration of contrast medium here instead of basal-bolus principle the examination window has been extended in time, thus allowing a more precise consideration [73]. The accuracy of CEUS in the recognition and classification of endoleaks 
Fig. 6 Endoleak after endovascular aortic aneurysm repair on CEUS imaging. a Typ 2 endoleak with enhancement of the aneurysm sac (arrow) caused by retrograde flow form a lumbar artery on CEUS imaging (left side) and corresponding B-mode ultrasound (right side). b Typ 1 endoleak with enhancement of the aneurysm sac (arrow) by an incomplete seal at the proximal end of the graft (main body) on CEUS imaging (left side) and corresponding B-mode ultrasound (right side)
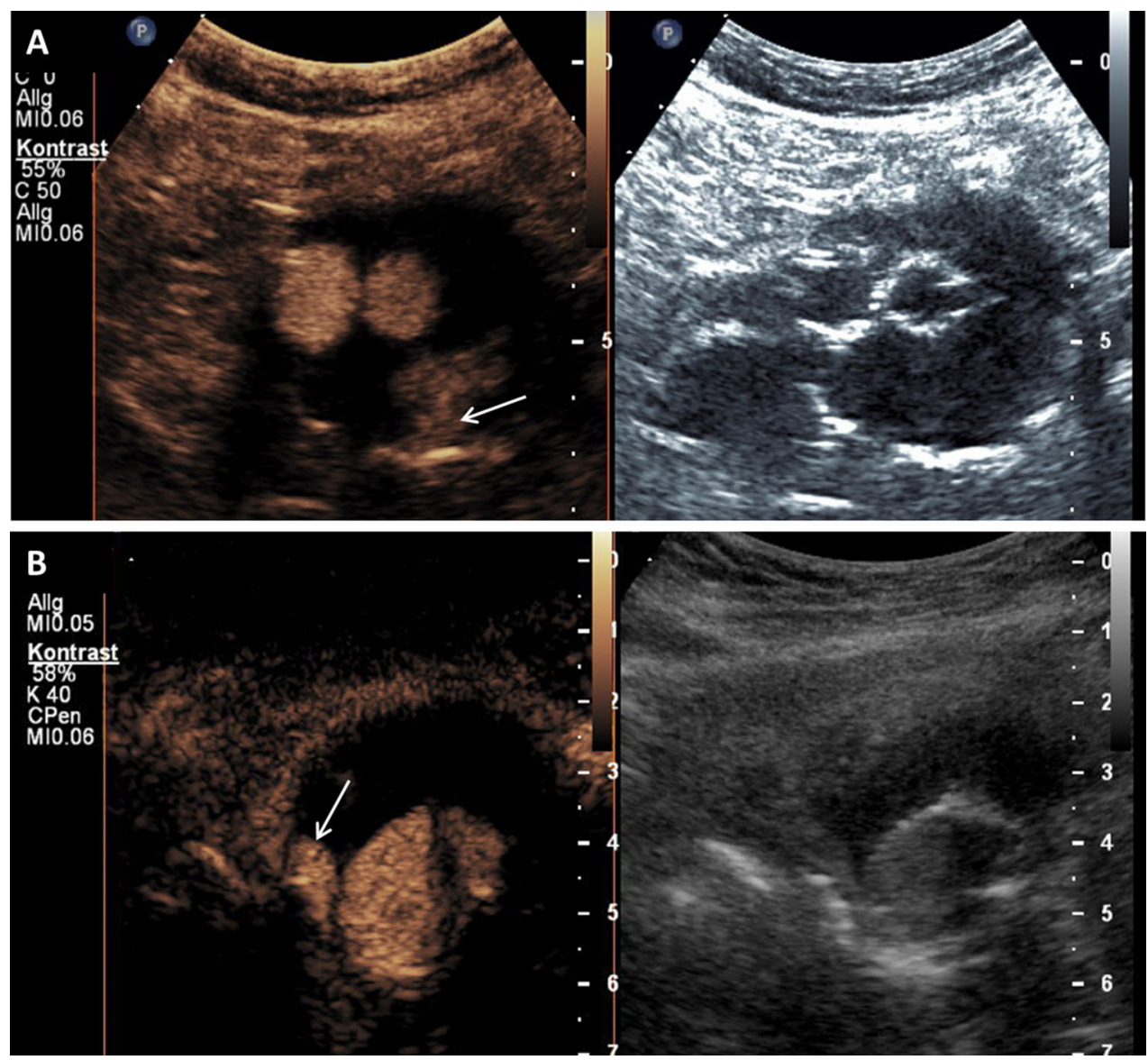

after EVAR seems to be high, as recently demonstrated prospectively with a sensitivity of $97 \%$, a specificity of $100 \%$ and an accuracy of $99 \%$ [74].

\section{D-CEUS for endoleak detection}

As a further development of CEUS, a novel technique for three-dimensional CEUS (3D-CEUS) utilizes positional information from magnetic field emitters to assemble all ultrasonic reflections into a high-definition three-dimensional image [75]. Ormesher et al. [76] stated, that in patients undergoing conventional infrarenal EVAR electively this 3D-CEUS technique allows intraoperatively the detection of endoleaks not seen on unipolar digital subtraction angiography and is more sensitive in finding the source of endoleak than conventional CEUS. This led to the authors implication that 3D-CEUS has the potential to complement or even to replace digital subtraction angiography in this context as final imaging in reduction of x-ray contrast. In another study, which was conducted by the same research group, the authors conclude that 3D may be more sensitive in assessing an endoleaks after EVAR than 2D CEUS or CTA [75].

Hopes for the future are through the use of CEUS periinterventionally during EVAR to improve risk stratification with respect to the occurrence of complications, so that therapy management or the follow-up intervals can be individually customized.

\section{Future directions in cardiovascular CEUS}

Ultrasound imaging using microbubbles which are targeted with monoclonal antibodies to specific ligands could further improve and expand the diagnostic prospects of current cardiovascular ultrasound examination in the future. The use of such targeted microbubbles may allow noninvasively investigating specific molecular processes that play a role in the pathophysiology of cardiovascular diseases [77].

In atherosclerosis, targeted microbubbles have been examined in the assessment of thrombosis, neoangiogenesis and inflammation in various animal models. Wang and co-workers investigated CEUS imaging with glycoprotein IIb/IIIa-targeted microbubbles which bind specifically to activated platelets [78]. They imaged the carotid artery in a mice model after thrombus induction and after thrombolysis. This imaging method allowed real-time molecular imaging of acute arterial thrombosis and monitoring of the success or failure of 
pharmacological thrombolysis in vivo. In a mouse model of age-dependent atherosclerosis, ultrasound molecular imaging of the proximal thoracic aorta was performed with microbubbles targeted to P-selectin and VCAM-1 in order to detect a lesion-prone vascular phenotype [79]. Both, P-selectin and VCAM-1 are involved in the regulation of leukocyte trafficking. This is an early step in inflammatory process involved in plaque formation. The researchers found that this targeted microbubbles preferentially bind to regions of lesion formation. Using this same mouse model, targeted microbubbles to VCAM-1 for CEUS imaging was used to investigate also the effect of statins to this early atherosclerosis process [80]. Less endothelial expression of VCAM- 1 and reduced plaque burden was found in statin treated animals. Accordingly, signal enhancement by CEUS molecular imaging was detected only in non-treated, but not in statin-treated animals. Monitoring these early changes of an activated and inflamed endothelium during the atherosclerotic process is appealing and has already made its way to preclinical studies in non-human primates [81]. Molecular ultrasound imaging has also been used to investigate a later stage of atherosclerotic disease by using VEGF-receptor targeted microbubbles in order to detect neovascularization on the abdominal artery plaques in rabbits [82]. This could be helpful to better risk stratify atherosclerotic lesions by imaging more specifically vulnerable plaques. However, no clinical studies using molecular ultrasound imaging in cardiovascular disease have been performed so far. Therefore, further studies are needed to bring the targeted microbubbles technology successfully forward from the laboratory to the clinical setting.

Moreover, ultrasound contrast agent has the potential to even further increase not only the diagnostic but also the therapeutic capabilities of ultrasound technology in the cardiovascular field. Several researchers are already investigating ultrasound directed and site-specific gene and drug delivery systems [83]. Particularly, the use of small molecules or plasmid DNA for thrombolysis, anti-inflammatory or anti- or angiogenic treatment could have an important clinical impact. Eventually, these newer techniques of theragnostic CEUS with the possibility to improve diagnostic imaging and directly treat the patient could be of great clinical benefit in the field of atherosclerosis.

\section{Complaince with ethical standards}

Disclosures Daniel Staub is supported by grants from the Swiss National Science Foundation (Grant PZOOP3_142419 and PBZHB120997), the Swiss Society of Angiology, the University of Basel and by an unrestricted research grant from Bracco Suisse SA, Manno, Switzerland.
Open Access This article is distributed under the terms of the Creative Commons Attribution 4.0 International License (http://crea tivecommons.org/licenses/by/4.0/), which permits unrestricted use, distribution, and reproduction in any medium, provided you give appropriate credit to the original author(s) and the source, provide a link to the Creative Commons license, and indicate if changes were made.

\section{References}

1. Feinstein S, Coll B, Staub D, Adam D, Schinkel A, ten Cate F, Thomenius K (2010) Contrast enhanced ultrasound imaging. J Nucl Cardiol 17(1):106-115. doi:10.1007/s12350-009-9165-y

2. Staub D, Schinkel A, Coll B, Coli S, van der Steen A, Reed J, Krueger C, Thomenius K, Adam D, Sijbrands E, ten Cate F, Feinstein S (2010) Contrast-enhanced ultrasound imaging of the vasa vasorum: from early atherosclerosis to the identification of unstable plaques. JACC Cardiovasc Imaging 3(7):761-771. doi:10.1016/j.jcmg.2010.02.007

3. ten Kate GL, Sijbrands EJ, Staub D, Coll B, ten Cate FJ, Feinstein SB, Schinkel AF (2010) Noninvasive imaging of the vulnerable atherosclerotic plaque. Curr Probl Cardiol 35(11):556-591. doi:10.1016/j.cpcardiol.2010.09.002

4. Senior R, Becher H, Monaghan M, Agati L, Zamorano J, Vanoverschelde JL, Nihoyannopoulos P (2009) Contrast echocardiography: evidence-based recommendations by European Association of Echocardiography. Eur J Echocardiogr 10(2):194-212. doi:10.1093/ejechocard/jep005

5. Mulvagh SL, Rakowski H, Vannan MA, Abdelmoneim SS, Becher H, Bierig SM, Burns PN, Castello R, Coon PD, Hagen ME, Jollis JG, Kimball TR, Kitzman DW, Kronzon I, Labovitz AJ, Lang RM, Mathew J, Moir WS, Nagueh SF, Pearlman AS, Perez JE, Porter TR, Rosenbloom J, Strachan GM, Thanigaraj S, Wei K, Woo A, Yu EH, Zoghbi WA, American Society of E (2008) American society of echocardiography consensus statement on the clinical applications of ultrasonic contrast agents in echocardiography. J Am Soc Echocardiogr 21 (11):1179-1201; quiz 1281. doi: 10.1016/j.echo.2008.09.009

6. Main ML, Ryan AC, Davis TE, Albano MP, Kusnetzky LL, Hibberd M (2008) Acute mortality in hospitalized patients undergoing echocardiography with and without an ultrasound contrast agent (multicenter registry results in 4,300,966 consecutive patients). Am J Cardiol 102(12):1742-1746. doi:10.1016/j. amjcard.2008.08.019

7. Main ML, Hibberd MG, Ryan A, Lowe TJ, Miller P, Bhat G (2014) Acute mortality in critically ill patients undergoing echocardiography with or without an ultrasound contrast agent. JACC Cardiovasc Imaging 7(1):40-48. doi:10.1016/j.jcmg.2013. 08.012

8. Porter TR, Abdelmoneim S, Belcik JT, McCulloch ML, Mulvagh SL, Olson JJ, Porcelli C, Tsutsui JM, Wei K (2014) Guidelines for the cardiac sonographer in the performance of contrast echocardiography: a focused update from the American Society of Echocardiography. J Am Soc Echocardiogr 27(8):797-810. doi:10.1016/j.echo.2014.05.011

9. Hoffmann R, Barletta G, von Bardeleben S, Vanoverschelde JL, Kasprzak J, Greis C, Becher H (2014) Analysis of left ventricular volumes and function: a multicenter comparison of cardiac magnetic resonance imaging, cine ventriculography, and unenhanced and contrast-enhanced two-dimensional and three-dimensional echocardiography. J Am Soc Echocardiogr 27(3):292301. doi:10.1016/j.echo.2013.12.005

10. Kurt M, Shaikh KA, Peterson L, Kurrelmeyer KM, Shah G, Nagueh SF, Fromm R, Quinones MA, Zoghbi WA (2009) Impact 
of contrast echocardiography on evaluation of ventricular function and clinical management in a large prospective cohort. J Am Coll Cardiol 53(9):802-810. doi:10.1016/j.jacc.2009.01.005

11. Malhotra V, Nwogu J, Bondmass MD, Bean M, Bieniarz T, Tertell M, Conliss M, Devries S (2000) Is the technically limited echocardiographic study an endangered species? endocardial border definition with native tissue harmonic imaging and Optison contrast: a review of 200 cases. J Am Soc Echocardiogr 13(8):771-773

12. Rainbird AJ, Mulvagh SL, Oh JK, McCully RB, Klarich KW, Shub C, Mahoney DW, Pellikka PA (2001) Contrast dobutamine stress echocardiography: clinical practice assessment in 300 consecutive patients. J Am Soc Echocardiogr 14(5):378-385

13. Thanigaraj S, Schechtman KB, Perez JE (1999) Improved echocardiographic delineation of left ventricular thrombus with the use of intravenous second-generation contrast image enhancement. J Am Soc Echocardiogr 12(12):1022-1026

14. Weinsaft JW, Kim RJ, Ross M, Krauser D, Manoushagian S, LaBounty TM, Cham MD, Min JK, Healy K, Wang Y, Parker M, Roman MJ, Devereux RB (2009) Contrast-enhanced anatomic imaging as compared to contrast-enhanced tissue characterization for detection of left ventricular thrombus. JACC Cardiovasc Imaging 2(8):969-979. doi:10.1016/j.jcmg.2009.03.017

15. Weinsaft JW, Kim HW, Crowley AL, Klem I, Shenoy C, Van Assche L, Brosnan R, Shah DJ, Velazquez EJ, Parker M, Judd RM, Kim RJ (2011) LV thrombus detection by routine echocardiography: insights into performance characteristics using delayed enhancement CMR. JACC Cardiovasc Imaging 4(7):702-712. doi:10.1016/j.jcmg.2011.03.017

16. Porter TR, Xie F (2010) Myocardial perfusion imaging with contrast ultrasound. JACC Cardiovasc Imaging 3(2):176-187. doi:10.1016/j.jcmg.2009.09.024

17. Senior R, Moreo A, Gaibazzi N, Agati L, Tiemann K, Shivalkar B, von Bardeleben S, Galiuto L, Lardoux H, Trocino G, Carrio I, Le Guludec D, Sambuceti G, Becher H, Colonna P, Ten Cate F, Bramucci E, Cohen A, Bezante G, Aggeli C, Kasprzak JD (2013) Comparison of sulfur hexafluoride microbubble (SonoVue)-enhanced myocardial contrast echocardiography with gated singlephoton emission computed tomography for detection of significant coronary artery disease: a large European multicenter study. J Am Coll Cardiol 62(15):1353-1361. doi:10.1016/j.jacc.2013. 04.082

18. Sillesen H (2014) Carotid Intima-media thickness and/or carotid plaque: what is relevant? Eur J Vasc Endovasc Surg. doi:10.1016/ j.ejvs.2014.04.026

19. Den Ruijter HM, Peters SA, Anderson TJ, Britton AR, Dekker JM, Eijkemans MJ, Engström G, Evans GW, de Graaf J, Grobbee DE, Hedblad B, Hofman A, Holewijn S, Ikeda A, Kavousi M, Kitagawa K, Kitamura A, Koffijberg H, Lonn EM, Lorenz MW, Mathiesen EB, Nijpels G, Okazaki S, O’Leary DH, Polak JF, Price JF, Robertson C, Rembold CM, Rosvall M, Rundek T, Salonen JT, Sitzer M, Stehouwer CD, Witteman JC, Moons KG, Bots ML (2012) Common carotid intima-media thickness measurements in cardiovascular risk prediction: a meta-analysis. JAMA 308(8):796-803. doi:10.1001/jama.2012.9630

20. Ziegelbauer K, Schaefer C, Steinmetz H, Sitzer M, Lorenz MW (2013) Clinical usefulness of carotid ultrasound to improve stroke risk assessment: ten-year results from the carotid atherosclerosis progression study (CAPS). Eur J Prev Cardiol 20(5):837-843. doi: $10.1177 / 2047487312449589$

21. Nambi V, Chambless L, Folsom AR, He M, Hu Y, Mosley T, Volcik K, Boerwinkle E, Ballantyne CM (2010) Carotid intimamedia thickness and presence or absence of plaque improves prediction of coronary heart disease risk: the ARIC (atherosclerosis risk in communities) study. J Am Coll Cardiol 55(15): 1600-1607. doi:10.1016/j.jacc.2009.11.075
22. van den Oord SC, Sijbrands EJ, ten Kate GL, van Klaveren D, van Domburg RT, van der Steen AF, Schinkel AF (2013) Carotid intima-media thickness for cardiovascular risk assessment: systematic review and meta-analysis. Atherosclerosis 228(1):1-11. doi:10.1016/j.atherosclerosis.2013.01.025

23. Eyding J, Geier B, Staub D (2011) Current strategies and possible perspectives of ultrasonic risk stratification of ischemic stroke in internal carotid artery disease. Ultraschall Med 32(3):267-273. doi:10.1055/s-0029-1245924

24. Nicolaides AN, Kakkos SK, Kyriacou E, Griffin M, Sabetai M, Thomas DJ, Tegos T, Geroulakos G, Labropoulos N, Doré CJ, Morris TP, Naylor R, Abbott AL, Group ACSaRoSAS (2010) Asymptomatic internal carotid artery stenosis and cerebrovascular risk stratification. J Vasc Surg 52 (6):1486-1496.e1481-1485. doi: 10.1016/j.jvs.2010.07.021

25. Naylor AR, Schroeder TV, Sillesen H (2014) Clinical and imaging features associated with an increased risk of late stroke in patients with asymptomatic carotid disease. Eur $\mathrm{J}$ Vasc Endovasc Surg 48(6):633-640. doi:10.1016/j.ejvs.2014.08.017

26. Madani A, Beletsky V, Tamayo A, Munoz C, Spence JD (2011) High-risk asymptomatic carotid stenosis: ulceration on 3D ultrasound vs TCD microemboli. Neurology 77(8):744-750. doi:10.1212/WNL.0b013e31822b0090

27. Prabhakaran S, Rundek T, Ramas R, Elkind MS, Paik MC, BodenAlbala B, Sacco RL (2006) Carotid plaque surface irregularity predicts ischemic stroke: the northern Manhattan study. Stroke 37(11):2696-2701. doi:10.1161/01.STR.0000244780.82190.a4

28. Partovi S, Loebe M, Aschwanden M, Baldi T, Jäger KA, Feinstein SB, Staub D (2012) Contrast-enhanced ultrasound for assessing carotid atherosclerotic plaque lesions. AJR Am J Roentgenol 198(1):W13-W19. doi:10.2214/AJR.11.7312

29. van den Oord SC, ten Kate GL, Sijbrands EJ, van der Steen AF, Schinkel AF (2013) Effect of carotid plaque screening using contrast-enhanced ultrasound on cardiovascular risk stratification. Am J Cardiol 111(5):754-759. doi:10.1016/j.amjcard.2012.11. 033

30. Staub D, Partovi S, Imfeld S, Uthoff H, Baldi T, Aschwanden M, Jaeger K (2013) Novel applications of contrast-enhanced ultrasound imaging in vascular medicine. Vasa 42(1):17-31. doi:10. 1024/0301-1526/a000244

31. Ventura CA, da Silva ES, Cerri GG, Leao PP, Tachibana A, Chammas MC (2015) Can contrast-enhanced ultrasound with second-generation contrast agents replace computed tomography angiography for distinguishing between occlusion and pseudoocclusion of the internal carotid artery? Clinics 70(1):1-6. doi:10. 6061/clinics/2015(01)01

32. Clevert DA, Sommer WH, Helck A, Reiser M (2011) Duplex and contrast enhanced ultrasound (CEUS) in evaluation of in-stent restenosis after carotid stenting. Clin Hemorheol Microcirc 48(1):199-208. doi:10.3233/CH-2011-1400

33. Sluimer J, Daemen M (2009) Novel concepts in atherogenesis: angiogenesis and hypoxia in atherosclerosis. J Pathol 218(1):7-29

34. Hellings WE, Peeters W, Moll FL, Piers SR, van Setten J, Van der Spek PJ, de Vries JP, Seldenrijk KA, De Bruin PC, Vink A, Velema E, de Kleijn DP, Pasterkamp G (2010) Composition of carotid atherosclerotic plaque is associated with cardiovascular outcome: a prognostic study. Circulation 121(17):1941-1950. doi:10.1161/CIRCULATIONAHA.109.887497

35. Gallino A, Stuber M, Crea F, Falk E, Corti R, Lekakis J, Schwitter J, Camici P, Gaemperli O, Di Valentino M, Prior J, GarciaGarcia HM, Vlachopoulos C, Cosentino F, Windecker S, Pedrazzini G, Conti R, Mach F, De Caterina R, Libby P (2012) "In vivo" imaging of atherosclerosis. Atherosclerosis 224(1):2536. doi:10.1016/j.atherosclerosis.2012.04.007

36. You X, Huang P, Zhang C, Wang M, Zhang Y, Hong Y, Wei S, Liu C, Pu Z, Zhang J, Chen S (2014) Relationship between enhanced 
intensity of contrast enhanced ultrasound and microvessel density of aortic atherosclerostic plaque in rabbit model. PLoS ONE 9(4):e92445. doi:10.1371/journal.pone.0092445

37. Moguillansky D, Leng X, Carson A, Lavery L, Schwartz A, Chen X, Villanueva FS (2011) Quantification of plaque neovascularization using contrast ultrasound: a histologic validation. Eur Heart J 32(5):646-653. doi:10.1093/eurheartj/ehq197

38. Schinkel A, Krueger C, Tellez A, Granada J, Reed J, Hall A, Zang W, Owens C, Kaluza G, Staub D, Coll B, Ten Cate F, Feinstein S (2010) Contrast-enhanced ultrasound for imaging vasa vasorum: comparison with histopathology in a swine model of atherosclerosis. Eur J Echocardiogr. doi:10.1093/ejechocard/ jeq048

39. Coli S, Magnoni M, Sangiorgi G, Marrocco-Trischitta M, Melisurgo G, Mauriello A, Spagnoli L, Chiesa R, Cianflone D, Maseri A (2008) Contrast-enhanced ultrasound imaging of intraplaque neovascularization in carotid arteries: correlation with histology and plaque echogenicity. J Am Coll Cardiol 52(3):223-230

40. Shah F, Balan P, Weinberg M, Reddy V, Neems R, Feinstein M, Dainauskas J, Meyer P, Goldin M, Feinstein S (2007) Contrastenhanced ultrasound imaging of atherosclerotic carotid plaque neovascularization: a new surrogate marker of atherosclerosis? Vasc Med 12(4):291-297

41. Hoogi A, Adam D, Hoffman A, Kerner H, Reisner S, Gaitini D (2011) Carotid plaque vulnerability: quantification of neovascularization on contrast-enhanced ultrasound with histopathologic correlation. AJR Am J Roentgenol 196(2):431-436. doi:10.2214/ AJR.10.4522

42. Vavuranakis M, Sigala F, Vrachatis DA, Papaioannou TG, Filis K, Kavantzas N, Kalogeras KI, Massoura C, Toufektzian L, Kariori MG, Vlasseros I, Kallikazaros I, Stefanadis C (2013) Quantitative analysis of carotid plaque vasa vasorum by CEUS and correlation with histology after endarterectomy. Vasa 42(3):184-195. doi:10.1024/0301-1526/a000267

43. Lisowska A, Knapp M, Tycinska A, Sawicki R, Kralisz P, Lisowski P, Sobkowicz B, Musial WI (2014) Usefulness of automatic measurement of contrast flow intensity: an innovative tool in contrast-enhanced ultrasound imaging of atherosclerotic carotid plaque neovascularization. A pilot study. Int Angiol J Int Union Angiol 33(1):50-57

44. van den Oord SC, Akkus Z, Bosch JG, Hoogi A, Ten Kate GL, Renaud G, Sijbrands EJ, Verhagen HJ, van der Lugt A, Adam D, de Jong N, van der Steen AF, Schinkel AF (2015) Quantitative contrast-enhanced ultrasound of intraplaque neovascularization in patients with carotid atherosclerosis. Ultraschall Med 36(2):154161. doi: $10.1055 / \mathrm{s}-0034-1366410$

45. Li C, He W, Guo D, Chen L, Jin X, Wang W, Huang B (2014) Quantification of carotid plaque neovascularization using contrast-enhanced ultrasound with histopathologic validation. Ultrasound Med Biol 40(8):1827-1833. doi:10.1016/j.ultrasmedbio. 2014.02.010

46. Müller HF, Viaccoz A, Kuzmanovic I, Bonvin C, Burkhardt K, Bochaton-Piallat ML, Sztajzel R (2014) Contrast-enhanced ultrasound imaging of carotid plaque neo-vascularization: accuracy of visual analysis. Ultrasound Med Biol 40(1):18-24. doi:10. 1016/j.ultrasmedbio.2013.08.012

47. Staub D, Partovi S, Schinkel AF, Coll B, Uthoff H, Aschwanden M, Jaeger KA, Feinstein SB (2011) Correlation of carotid artery atherosclerotic lesion echogenicity and severity at standard US with intraplaque neovascularization detected at contrast-enhanced US. Radiology 258(2):618-626. doi:10.1148/radiol.10101008

48. Zhou Y, Xing Y, Li Y, Bai Y, Chen Y, Sun X, Zhu Y, Wu J (2013) An assessment of the vulnerability of carotid plaques: a comparative study between intraplaque neovascularization and plaque echogenicity. BMC Med Imaging 13:13. doi:10.1186/ 1471-2342-13-13
49. Staub D, Patel M, Tibrewala A, Ludden D, Johnson M, Espinosa P, Coll B, Jaeger K, Feinstein S (2010) Vasa vasorum and plaque neovascularization on contrast-enhanced carotid ultrasound imaging correlates with cardiovascular disease and past cardiovascular events. Stroke 41(1):41-47

50. Xiong L, Deng Y, Zhu Y, Liu Y, Bi X (2009) Correlation of carotid plaque neovascularization detected by using contrast-enhanced US with clinical symptoms. Radiology 251(2):583-589

51. Faggioli GL, Pini R, Mauro R, Pasquinelli G, Fittipaldi S, Freyrie A, Serra C, Stella A (2011) Identification of carotid 'vulnerable plaque' by contrast-enhanced ultrasonography: correlation with plaque histology, symptoms and cerebral computed tomography. Eur J Vasc Endovasc Surg 41(2):238-248. doi:10.1016/j.ejvs. 2010.11.002

52. Saito K, Nagatsuka K, Ishibashi-Ueda H, Watanabe A, Kannki H, Iihara K (2014) Contrast-enhanced ultrasound for the evaluation of neovascularization in atherosclerotic carotid artery plaques. Stroke 45(10):3073-3075. doi:10.1161/STROKEAHA.114.006483

53. Piscaglia F, Nolsøe C, Dietrich CF, Cosgrove DO, Gilja OH, Bachmann Nielsen M, Albrecht T, Barozzi L, Bertolotto M, Catalano O, Claudon M, Clevert DA, Correas JM, D'Onofrio M, Drudi FM, Eyding J, Giovannini M, Hocke M, Ignee A, Jung EM, Klauser AS, Lassau N, Leen E, Mathis G, Saftoiu A, Seidel G, Sidhu PS, ter Haar G, Timmerman D, Weskott HP (2012) The EFSUMB Guidelines and Recommendations on the clinical practice of contrast enhanced ultrasound (CEUS): update 2011 on non-hepatic applications. Ultraschall Med 33(1):33-59. doi:10. 1055/s-0031-1281676

54. Tian J, Hu S, Sun Y, Yu H, Han X, Cheng W, Ban X, Zhang S, Yu B, Jang IK (2013) Vasa vasorum and plaque progression, and responses to atorvastatin in a rabbit model of atherosclerosis: contrast-enhanced ultrasound imaging and intravascular ultrasound study. Heart 99(1):48-54. doi:10.1136/heartjnl-2012302775

55. von Bierbrauer A, Dilger M, Fink T (2008) Acute aortic dissection-vascular emergency with numerous pitfalls. Vasa 37(1):53-59

56. Clevert DA, Schick K, Chen MH, Zhu QL, Reiser M (2009) Role of contrast enhanced ultrasound in detection of abdominal aortic abnormalities in comparison with multislice computed tomography. Chin Med J (Engl) 122(7):858-864

57. Schuster H, Dünser E, Osinger K, Bergmayr W, Fischer-Scholz U, Richter W, Mostbeck GH (2009) Ultrasound imaging of abdominal aortic aneurysms: diagnosis of aneurysms and complications and follow-up after endovascular repair. Ultraschall Med 30(6):528-543. doi:10.1055/s-0028-1109913

58. Clevert DA, Stickel M, Johnson T, Glaser C, Steitz HO, Kopp R, Jauch KW, Reiser M (2007) Imaging of aortic abnormalities with contrast-enhanced ultrasound. A pictorial comparison with CT. Eur Radiol 17(11):2991-3000. doi:10.1007/s00330-006-0542-5

59. Clevert DA, Horng A, Jung EM, Sommer WH, Reiser M (2009) Contrast-enhanced ultrasound versus conventional ultrasound and MS-CT in the diagnosis of abdominal aortic dissection. Clin Hemorheol Microcirc 43(1-2):129-139. doi:10.3233/CH-20091227

60. Catalano O, Lobianco R, Cusati B, Siani A (2005) Contrastenhanced sonography for diagnosis of ruptured abdominal aortic aneurysm. AJR Am J Roentgenol 184(2):423-427

61. Santosa F, Moysidis T, Nowak T, Heilmaier C, Berg C, Luther B, Kröger K (2012) Endovascular abdominal aneurysm repair: trends in Germany. Vasa 41(4):268-274. doi:10.1024/0301-1526/ a000202

62. Veith FJ, Baum RA, Ohki T, Amor M, Adiseshiah M, Blankensteijn JD, Buth J, Chuter TA, Fairman RM, Gilling-Smith G, Harris PL, Hodgson KJ, Hopkinson BR, Ivancev K, Katzen BT, Lawrence-Brown M, Meier GH, Malina M, Makaroun MS, Parodi JC, Richter GM, Rubin GD, Stelter WJ, White GH, White 
RA, Wisselink W, Zarins CK (2002) Nature and significance of endoleaks and endotension: summary of opinions expressed at an international conference. J Vasc Surg 35(5):1029-1035

63. Uthoff H, Pena C, Katzen BT, Gandhi R, West J, Benenati JF, Geisbüsch P (2012) Current clinical practice in postoperative endovascular aneurysm repair imaging suveillance. J Vasc Interv Radiol. doi:10.1016/j.jvir.2012.06.003

64. Verhoeven EL, Oikonomou K, Ventin FC, Lerut P, Fernandes EFR, Mendes PL (2011) Is it time to eliminate CT after EVAR as routine follow-up? J Cardiovasc Surg (Torino) 52(2):193-198

65. Mirza TA, Karthikesalingam A, Jackson D, Walsh SR, Holt PJ, Hayes PD, Boyle JR (2010) Duplex ultrasound and contrast-enhanced ultrasound versus computed tomography for the detection of endoleak after EVAR: systematic review and bivariate metaanalysis. Eur J Vasc Endovasc Surg 39(4):418-428. doi:10.1016/ j.ejvs.2010.01.001

66. Ashoke R, Brown LC, Rodway A, Choke E, Thompson MM, Greenhalgh RM, Powell JT (2005) Color duplex ultrasonography is insensitive for the detection of endoleak after aortic endografting: a systematic review. J Endovasc Ther 12(3):297-305. doi:10.1583/04-1479R.1

67. Napoli V, Bargellini I, Sardella SG, Petruzzi P, Cioni R, Vignali C, Ferrari M, Bartolozzi C (2004) Abdominal aortic aneurysm: contrast-enhanced US for missed endoleaks after endoluminal repair. Radiology 233(1):217-225. doi:10.1148/radiol.2331031767

68. Dill-Macky MJ, Wilson SR, Sternbach Y, Kachura J, Lindsay T (2007) Detecting endoleaks in aortic endografts using contrastenhanced sonography. AJR Am J Roentgenol 188(3):W262W268. doi:10.2214/AJR.05.0532

69. Kopp R, Zürn W, Weidenhagen R, Meimarakis G, Clevert DA (2010) First experience using intraoperative contrast-enhanced ultrasound during endovascular aneurysm repair for infrarenal aortic aneurysms. J Vasc Surg 51(5):1103-1110. doi:10.1016/j. jvs.2009.12.050

70. Jung EM, Rennert J, Fellner C, Uller W, Jung W, Schreyer A, Heiss P, Hoffstetter P, Feuerbach S, Kasparzk P, Zorger N, Pfister K (2010) Detection and characterization of endoleaks following endovascular treatment of abdominal aortic aneurysms using contrast harmonic imaging (CHI) with quantitative perfusion analysis (TIC) compared to CT angiography (CTA). Ultraschall Med 31(6):564-570. doi:10.1055/s-0028-1109811

71. Perini P, Sediri I, Midulla M, Delsart P, Mouton S, Gautier C, Pruvo JP, Haulon S (2011) Single-centre prospective comparison between contrast-enhanced ultrasound and computed tomography angiography after EVAR. Eur J Vasc Endovasc Surg 42(6):797802. doi:10.1016/j.ejvs.2011.09.003

72. Cantisani V, Ricci P, Grazhdani H, Napoli A, Fanelli F, Catalano C, Galati G, D'Andrea V, Biancari F, Passariello R (2011) Prospective comparative analysis of colour-Doppler ultrasound, contrast-enhanced ultrasound, computed tomography and magnetic resonance in detecting endoleak after endovascular abdominal aortic aneurysm repair. Eur J Vasc Endovasc Surg 41(2):186-192. doi:10.1016/j.ejvs.2010.10.003

73. Henao EA, Hodge MD, Felkai DD, McCollum CH, Noon GP, Lin PH, Lumsden AB, Bush RL (2006) Contrast-enhanced duplex surveillance after endovascular abdominal aortic aneurysm repair: improved efficacy using a continuous infusion technique.
J Vasc Surg 43 (2):259-264; discussion 264. doi:10.1016/j.jvs. 2005.09.045

74. Gilabert R, Buñesch L, Real MI, García-Criado A, Burrel M, Ayuso JR, Barrufet M, Montaña X, Riambau V (2012) Evaluation of abdominal aortic aneurysm after endovascular repair: prospective validation of contrast-enhanced US with a secondgeneration us contrast agent. Radiology 264(1):269-277. doi:10. 1148/radiol.12111528

75. Abbas A, Hansrani V, Sedgwick N, Ghosh J, McCollum CN (2014) 3D contrast enhanced ultrasound for detecting endoleak following endovascular aneurysm repair (EVAR). Eur J Vasc Endovasc Surg 47(5):487-492. doi:10.1016/j.ejvs.2014.02.002

76. Ormesher DC, Lowe C, Sedgwick N, McCollum CN, Ghosh J (2014) Use of three-dimensional contrast-enhanced duplex ultrasound imaging during endovascular aneurysm repair. J Vasc Surg 60(6):1468-1472. doi:10.1016/j.jvs.2014.08.095

77. Piedra M, Allroggen A, Lindner J (2009) Molecular imaging with targeted contrast ultrasound. Cerebrovasc Dis 27(Suppl 2):66-74

78. Wang X, Hagemeyer CE, Hohmann JD, Leitner E, Armstrong PC, Jia F, Olschewski M, Needles A, Peter K, Ahrens I (2012) Novel single-chain antibody-targeted microbubbles for molecular ultrasound imaging of thrombosis: validation of a unique noninvasive method for rapid and sensitive detection of thrombi and monitoring of success or failure of thrombolysis in mice. Circulation 125(25):3117-3126. doi:10.1161/CIRCULATIONAHA. 111.030312

79. Kaufmann BA, Carr CL, Belcik JT, Xie A, Yue Q, Chadderdon S, Caplan ES, Khangura J, Bullens S, Bunting S, Lindner JR (2010) Molecular imaging of the initial inflammatory response in atherosclerosis: implications for early detection of disease. Arterioscler Thromb Vasc Biol 30(1):54-59. doi:10.1161/ATV BAHA.109.196386

80. Khanicheh E, Mitterhuber M, Xu L, Haeuselmann SP, Kuster GM, Kaufmann BA (2013) Noninvasive ultrasound molecular imaging of the effect of statins on endothelial inflammatory phenotype in early atherosclerosis. PLoS ONE 8(3):e58761. doi:10.1371/journal.pone.0058761

81. Chadderdon SM, Belcik JT, Bader L, Kirigiti MA, Peters DM, Kievit P, Grove KL, Lindner JR (2014) Proinflammatory endothelial activation detected by molecular imaging in obese nonhuman primates coincides with onset of insulin resistance and progressively increases with duration of insulin resistance. Circulation 129(4):471-478. doi:10.1161/CIRCULATIONAHA. 113.003645

82. Liu H, Wang X, Tan KB, Liu P, Zhuo ZX, Liu Z, Hua X, Zhuo QQ, Xia HM, Gao YH (2011) Molecular imaging of vulnerable plaques in rabbits using contrast-enhanced ultrasound targeting to vascular endothelial growth factor receptor-2. J Clin Ultrasound 39(2):83-90. doi:10.1002/jcu.20759

83. Castle J, Butts M, Healey A, Kent K, Marino M, Feinstein SB (2013) Ultrasound-mediated targeted drug delivery: recent success and remaining challenges. Am J Physiol Heart Circ Physiol 304(3):H350-H357. doi:10.1152/ajpheart.00265.2012

84. Schinkel AF (2015) Contrastechocardiografie. In: Hamer JPM (ed) Praktische echocardiografie Bohn Stafleu van Lochem, 3rd edn. Springer Media, Netherlands 